\title{
Compare NDVI extracted from Landsat 8 imagery with that from Landsat 7 imagery
}

\author{
Dandan Xu* , Xulin Guo \\ Department of Geography and Planning, University of Saskatchewan, Saskatoon, Canada
}

Email address:

dax890@mail.usask.ca (Dandan Xu); xulin.guo@usask.ca (Xulin Guo)

\section{To cite this article:}

Dandan Xu, Xulin Guo. Compare NDVI Extracted from Landsat 8 Imagery with that from Landsat 7 Imagery. American Journal of Remote Sensing. Vol. 2, No. 2, 2014, pp. 10-14. doi: 10.11648/j.ajrs.20140202.11

\begin{abstract}
Landsat 8, the ongoing mission of the Landsat satellites that have provided over 40 years of images, continues to benefit long-term research. However, it is important to know if the spectral features of Landsat 8 are of the same standard as previous Landsat imagery because Landsat 8 images have narrower bands, especially because of the normalized difference vegetation index (NDVI) calculation which is the most popular vegetation index. In this study NDVI values derived from Landsat 8 images were compared with those calculated from Landsat 7 and ground measured hyperspectral data. The result shows that Landsat 8 NDVI is larger than Landsat 7 NDVI in lower vegetation covered areas and the difference becomes smaller as the value of NDVI increases. This indicates that NDVI of Landsat 7 and Landsat 8 is consistent when dealing with high vegetation covered areas (e.g. forest area and tall grass prairie) because the difference between Landsat 7 and 8 NDVI is close to zero when the value of NDVI is high, but this needs to be further investigated. There is also further need for calibration of NDVI in low vegetation covered areas in order to achieve consistency between Landsat 7 and Landsat 8 images.
\end{abstract}

Keywords: Remote Sensing, Landsat 8, OLI, LDCM, Landsat 7, ETM+, NDVI, ATCOR

\section{Introduction}

Landsat, with high spatial resolution and standardized normalized difference vegetation index (NDVI) data, has been widely used in biophysical feature extraction (biomass, green cover, net primary productivity), climate change (phenology), ecological and hydrological modeling and more for over 40 years [1-7]. Landsat has the potential to offer a long-term NDVI products at both a regional and global scale which is superior to that of low spatial resolution NDVI products of AVHRR NDVI (1989-present with $1 \mathrm{~km}$ spatial resolution; 1982-present with $8 \mathrm{~km}$ spatial resolution), MODIS NDVI (2000-present with $250 \mathrm{~m}, 500 \mathrm{~m}$ or $1 \mathrm{~km}$ spatial resolution) and VEGETATION NDVI (1999-present with $1.15 \mathrm{~km}$ spatial resolution [8-10]. The time series database for these Landsat images, including Landsat Multispectral Scanner (MSS), Landsat Thematic Mapper (TM), Landsat Enhanced Thematic Mapper Plus (ETM+) [11] and Landsat Operational Land Imager (OLI, Landsat 8) [1214] has a time series database of 42 years (1972-present) and a much higher spatial resolution (79 m before 1982 and $30 \mathrm{~m}$ after 1982); the caveat is that it is necessity to calibrate the NDVI extracted from different Landsat sensors in order to provide consistent and standardized NDVI products, as the Landsat 8 images have narrower red $(\mathrm{R})$ and near infrared (NIR) bands than ETM+ images (table 1) [15]. In this study two research questions will be be explored by comparing NDVI calculated from ETM+, OLI images and ground measured hyperspectral data in mixed grassland: first, how the narrower bands of Landsat 8 will influence NDVI value; second, how the NDVI extracted from Landsat 8 is calibrated with that from other Landsat sensors in long-term studies.

\section{Study Area and Data}

The study areas are the West Block of Grasslands National Park (GNP) $\left(49^{\circ} \mathrm{N}, 107^{\circ} \mathrm{W}\right)$ and the surrounding pastures, located in the southern part of Saskatchewan, Canada (Figure 1). The annual mean temperature and total precipitation of this area are $3.4{ }^{\circ} \mathrm{C}$ and $340 \mathrm{~mm}$ respectively [16]. GNP falls within the semi-arid mixed grassland ecosystem [17] which contains shrub, grassland and small lakes. The surrounding pastures also contain small areas of cropland. Twelve grassland sites were selected for their random stratified design and accessibility, including upland (4 samples), valley (3 samples) and slope (5 samples) grasslands. The plot design in each site was consistent with the field design of the 
historical field data in our research group [18] and the hyperspectral data of each quadrat was measured by ASD (Analytical Spectral Devices) field-portable FieldSpec ${ }^{\circledR}$ Pro Spectroradiometer. To correlate with Landsat Imagery, all the spectral data were averaged by plots and NDVI extracted from Landsat images was averaged by $3 \times 3$ pixels to match the field data as well.
The images used in this study are ETM+ 10 June 2013, ETM+ 26 June 2013 and OLI 18 June 2013, which are level 1 products that were downloaded from the U.S. Geological Survey (USGS) website. All the images were taken during the maximum growing season of grasslands. For comparing Landsat 7 with Landsat 8, the area with no data from ETM+ images and cloud coverage of ETM+ 10 June 2013 were masked out (Figure 1).

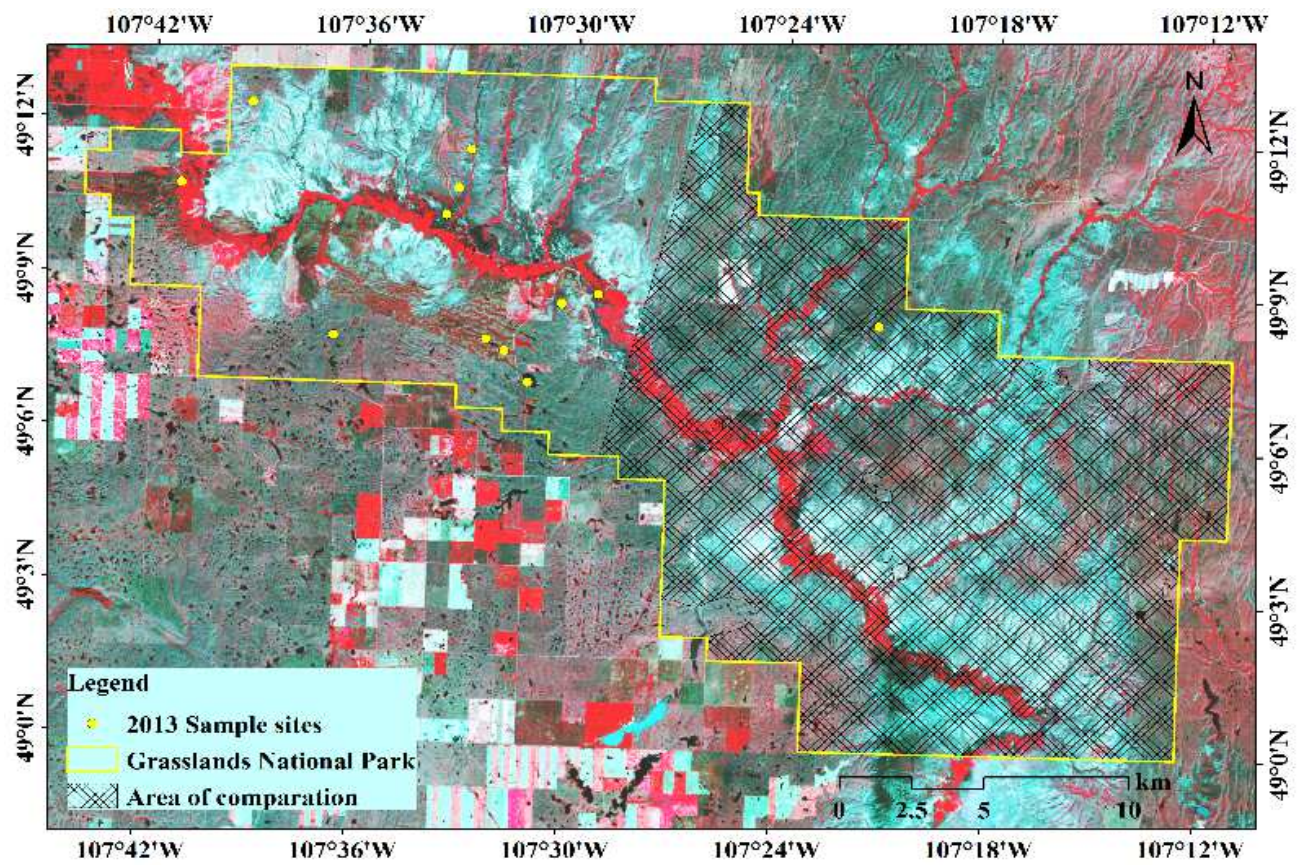

Figure 1. Study area (the background image is the standard false color composition of the Landsat 8 image acquired on 18 June 2013).

Table 1. Multispectral bands of Landsat 7 and Landsat 8

\begin{tabular}{llllc}
\hline Landsat 8 OLI & Wavelength (um) & Spatial resolution(m) & Landsat 7 ETM+ & Wavelength (um) \\
\hline Band 1 - Coastal aerosol & $0.43-0.45$ & 30 & & Spatial resolution (m) \\
Band 2 - Blue & $0.45-0.51$ & 30 & Band 1 & $0.45-0.52$ \\
Band 3 - Green & $0.53-0.59$ & 30 & Band 2 & $0.52-0.60$ \\
Band 4 - Red & $0.64-0.67$ & 30 & Band 3 & $0.63-0.69$ \\
Band 5 - Near Infrared (NIR) & $0.85-0.88$ & 30 & Band 4 & $0.77-0.90$ \\
Band 6 - SWIR 1 & $1.57-1.65$ & 30 & Band 5 & $1.55-1.75$ \\
Band 7 - SWIR 2 & $2.11-2.29$ & 30 & Band 7 & $2.09-2.35$ \\
Band 8 - Panchromatic & $0.50-0.68$ & 15 & Band 8 & 30 \\
Band 9 - Cirrus & $1.36-1.38$ & 30 & & 30 \\
\hline
\end{tabular}

\section{Method}

The images were geometrically corrected by Level 1 product generation system (LPGS). Ground reflectance atmospheric correction was conducted for all three images using ATCOR in PCI Geomatica 2013 (gain and offset were calculated by Equation 1 and Equation 2). Haze correction was only applied for the bands under 0.85 micrometers and the elevation was set up as a constant height $(778 \mathrm{~m})$ because the study area is flat.

$$
B=L_{\min }-\left(\frac{L_{\max }-L_{\min }}{Q_{\max }-Q_{\min }}\right) \times Q_{\min }
$$

$$
G=\frac{L_{\max }-L_{\min }}{Q_{\max }-Q_{\min }}
$$

Where $B$ is offset; $G$ is gain; $L_{\min }$ and $L_{\max }$ is "LMIN_BAND" and "LMAX_BAND" in the image metadata file, which are the minimum and maximum spectral radiance corresponding to $Q_{\min }$ and $Q_{\max } ; Q_{\min }$ and $Q_{\max }$ is the minimum and the maximum digital count value. $Q_{\min }$ and $Q_{\max }$ is 1 and 255 for Landsat ETM+ images and $Q_{\min }$ and $Q_{\max }$ is 1 and 65535 [19].

All three atmospherically corrected images were clipped into the "compare area" in the study area (Figure 1). Four groups (water, shrub, grassland and cropland) were classified from the Landsat 8 image acquired on 18 June 2013 using 
supervised classification with maximum likelihood algorithm. NDVI was compared between Landsat 7 and Landsat 8 images within each group of the compared area. The NDVI comparison among the field measured hyper-spectra, simulated Landsat 7 and 8 reflectance and the comparison of hyperspectral NDVI and Landsat 8 NDVI are based on the field sample sites (Figure 1). Reflectance of red and nearinfrared bands for Landsat 7 and 8 is also simulated based on field measured hyperspectral data and spectral response functions of Landsat 7 and 8 [20] in order to calculate the simulated OLI NDVI and simulated ETM+ NDVI. In addition, a linear regression model in $\mathrm{R}$ software was applied to compare NDVI extracted from Landsat 7 images, a Landsat 8 image and field measured hyperspectral data.

To avoid the effects of phenology within the 8 day interval between Landsat 7 and 8 images, vegetation growth rate (Equation 3) for cropland, grassland and shrubland was calculated respectively using a MODIS product (MOD09Q1, surface reflectance band $1-2,8$ days composition). Then, to correlate with Landsat 8 NDVI of 18 June, the growth rate was used to simulate Landsat 7 NDVI of 18 June from Landsat 7 NDVI of 10 June and 26 June (Equation 4).

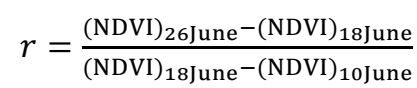

Where $r$ is the vegetation growth rate; (NDVI) $26 \mathrm{June}$, $(\mathrm{NDVI})_{10 \mathrm{June}}$ and (NDVI) ${ }_{10 \mathrm{June}}$ are NDVI of 26 June, 18 June and 10 June representatively.

$$
\mathrm{NDVI}_{\text {etm18June }}=\frac{(\mathrm{NDVI})_{\mathrm{etm} 26 \mathrm{June}}+r \times(\mathrm{NDVI})_{\text {etm10June }}}{1+r}
$$

Where $\mathrm{NDVI}_{\text {etm18June }}$ is the simulated Landsat 7 NDVI of 18 June; (NDVI) etm26June and (NDVI) etm10June $_{\text {are Landsat } 7}$ NDVI of 26 June and 10 June.

\section{Results}

\subsection{NDVI Comparison Between Landsat 7 and 8 Images}

The study area is dominated by grasslands and badlands with shrub along the river, small bodies of water and a small area of cropland (Figure 2). The overall accuracy for the classification is $84.3 \%$. The comparison of NDVI between Landsat 7 and Landsat 8 only contains cropland, shrubland and grassland because the whole study area contains only a small amount of pixels of water body and NDVI of badland has almost no vegetation cover.

The acquired date of the Landsat 8 image had an 8 day interval with the two ETM+ images and this caused slight changes in actual NDVI during this period, largely due to phenology. NDVI calculated from ETM + images, taken during 10 June to 26 June, increased because vegetation was growing. NDVI in grassland and shrub slightly increased while there was a dramatic increase in cropland NDVI (Figure 3). The vegetation growth rate (R, Equation 3 ) of shrubland, grassland and cropland was 1.16, 1.40 and 1.73 respectively. To minimize the effects of phenology on the comparison of NDVI between Landsat 7 and 8 (Figure 4), Landsat 7 NDVI from 18 June was simulated based on the vegetation growth rate (Equation 4 ).

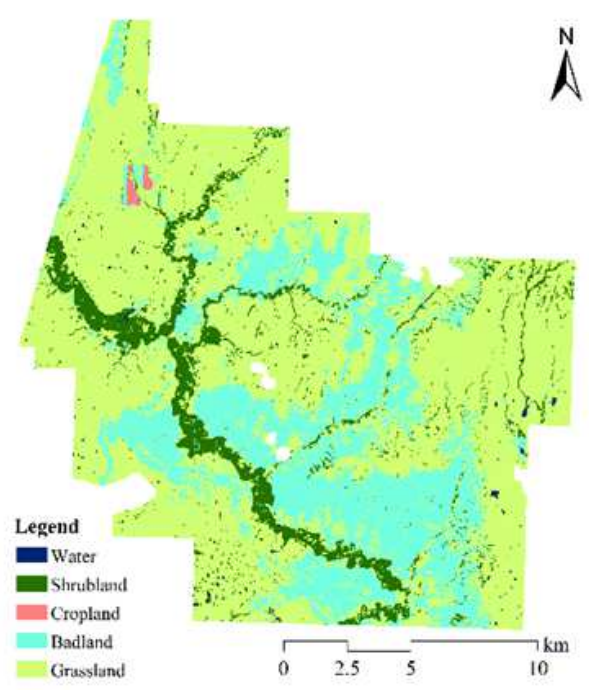

Figure 2. Five types of main land cover in the study area (the white areas are the cloud cover mask)
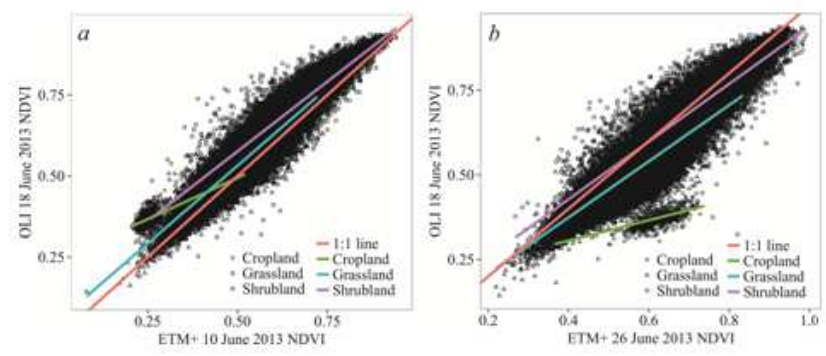

Figure 3. Comparison of NDVI extracted from OLI 18 June 2013 with that from two ETM+ images.

NDVI extracted from Landsat 8 images in grassland is slightly higher than that from Landsat 7 images while the difference between them becomes smaller when NDVI increases (Figure 4). Landsat 8 NDVI in the area covered by shrub is larger than that of Landsat 7 when vegetation cover is lower; however, the difference becomes smaller as NDVI increases (Figure 4). The result in croplands is quite different from grasslands and shrub areas (Figure 4).

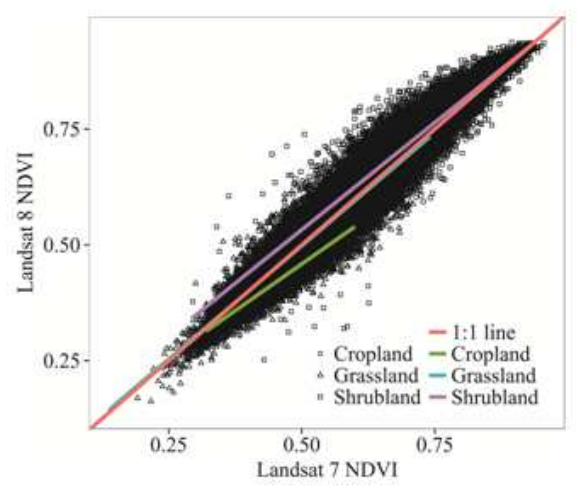

Figure 4. The comparison of Landsat 8 NDVI and Landsat 7 NDVI. 


\subsection{The Comparison of Simulated Landsat 7 and 8 NDVI}

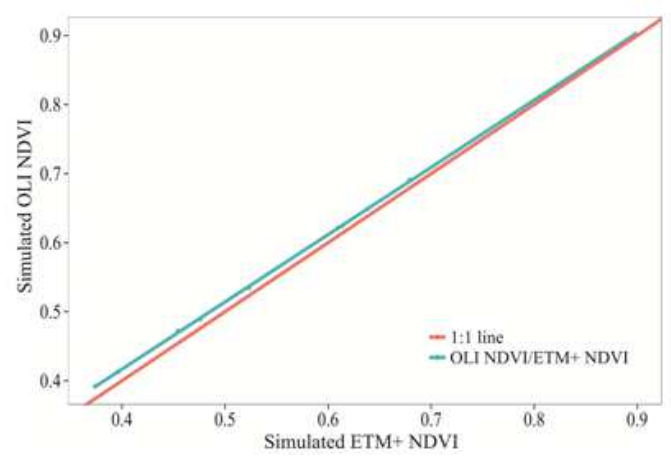

Figure 5. Simulated OLI NDVI and simulated ETM+ NDVI.

Simulated Landsat 7 and 8 NDVI was used to calibrate the comparison results of Landsat 7 and 8 image NDVI based on field measured spectra and spectral response function. When the value of NDVI is low, simulated OLI NDVI is slightly higher than simulated ETM+ NDVI; when high, simulated OLI NDVI is quite similar to simulated ETM+ NDVI (Figure 5). The relationship between simulated OLI NDVI and hyperspectral NDVI is similar to that between Landsat 7 and 8 NDVI in both grassland and shrubland.

\section{Discussion}

Crops grow quickly during 10 June to 26 June as this is the season of maximum growth which causes increases to NDVI in a large range. Phenology has a large effect on the comparison of Landsat 7 and 8 NDVI in cropland. Even with an 8-day frequency of data acquisition by combining the data of Landsat 7 and 8 together, it is hard to capture the detailed changes in vegetation throughout the cropland of the study area. The NDVI comparison of the two sensors in cropland is still not accurate because there are two different croplands in the study area (one cropland already has plants on 10 June while another one does not), despite having a simulated ETM+ NDVI for 18 June to correlate with OLI NDVI on the same day. Due to the cloud problem with MODIS data, only one vegetation growth rate was obtained for cropland.

When comparing Landsat 7 and 8 NDVI in grasslands, Landsat 8 NDVI is larger than Landsat 7 NDVI when the value of NDVI is low, supported by a similar result when comparing simulated OLI and ETM+ NDVI. Because of the large amount of dead material in the mixed grasslands of the study area, the high absorption in red band in the spectrum of mixed grasslands is not as clear as that of tall grass prairie and forest (Figure 6). Based on the field measured hyperspectral data, the reflectance of red band at Landsat 8 wavelength range (dark grey rectangle in Figure 7) is slightly smaller than that at Landsat 7 wavelength range (light grey rectangle in Figure 7). On the other hand, the near infrared reflectance of Landsat 8 is higher than that of Landsat 7 (Figure 6). This means that Landsat 8 NDVI is higher than Landsat 7 NDVI in mixed grasslands. In the areas with nearly no vegetation cover, the land surface features are normally rocks, bare soil and soil crust (moss and lichen), which have similar spectral signal. Based on the spectral signal of wet soil [21], near-infrared reflectance of Landsat 8 and 7 is similar but red reflectance for Landsat 8 is larger than that for Landsat 7. Landsat 8 NDVI is therefore lower than Landsat 7 NDVI in bare soil area and Landsat 8 images may detect lower NDVI for bare soil and higher NDVI for vegetation than $\mathrm{ETM}+$ images.

The comparison of NDVI in shrub land between Landsat 7 and 8 is similar to that in grasslands, which indicates Landsat 8 NDVI is larger than Landsat 7 NDVI when the value of NDVI is low while the difference becomes smaller as NDVI increases. Both NDVI values become similar when the value is high and so Landsat 7 and 8 NDVI may be consistent in forest or tall grass prairie, although further research is required to test this.

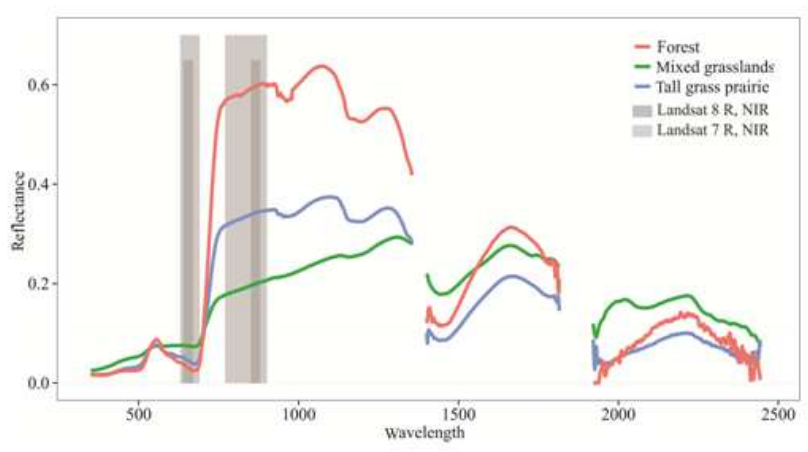

Figure 6. Spectra of mixed grasslands, tall grass prairie and forest [spectral data collected by our group over kansas Tallgrass Prairie and GNP, 22]

\section{Acknowledgement}

The authors would like to acknowledge Saskatchewan Innovation and Opportunity Graduate Scholarship and China Scholarship Council (CSC) for financial support as well as Grasslands National Park and the University of Saskatchewan for logistical support. The authors would also like to thank the field work crew (Tengfei Cui and Xiaolei $\mathrm{Yu}$ ) for field data collection.

\section{References}

[1] Frank, A.B., et al., Vegetation indices, CO2 flux, and biomass for Northern Plains Grasslands. Journal of Range Management, 2003. 56(4): p. 382-387.

[2] Chen, J., et al., Estimating aboveground biomass of grassland having a high canopy cover: an exploratory analysis of in situ hyperspectral data. International Journal of Remote Sensing, 2009. 30(24): p. 6497-6517.

[3] Jiang, Z., et al., Analysis of NDVI and scaled difference vegetation index retrievals of vegetation fraction. Remote sensing of Environment, 2006. 101(3): p. 366-378.

[4] Sims, D.A., et al., A new model of gross primary productivity for North American ecosystems based solely on the enhanced vegetation index and land surface temperature from MODIS. Remote sensing of Environment, 2008. 112(4): p. 1633-1646. 
[5] Ma, X., et al., Spatial patterns and temporal dynamics in savanna vegetation phenology across the North Australian Tropical Transect. Remote sensing of Environment, 2013. 139: p. 97-115.

[6] Cord, A.F., et al., Modelling species distributions with remote sensing data: bridging disciplinary perspectives. Journal of Biogeography, 2013. 40(12): p. 2226-2227.

[7] Jordan, Y.C., et al., Traits of surface water pollution under climate and land use changes: A remote sensing and hydrological modeling approach. Earth-Science Reviews, 2014. 128: p. 181-195.

[8] Barichivich, J., et al., Large-scale variations in the vegetation growing season and annual cycle of atmospheric CO2 at high northern latitudes from 1950 to 2011. Global change biology, 2013.

[9] Silva, F.B., et al., Large-scale heterogeneity of Amazonian phenology revealed from 26-year long AVHRR/NDVI timeseries. Environmental Research Letters, 2013. 8(2): p. 024011.

[10] USGS. NDVI from AVHRR. 2013 2013/08/30; Available from: http://phenology.cr.usgs.gov/ndvi_avhrr.php.

[11] Chander, G., et al., A Procedure for Radiometric Recalibration of Landsat 5 TM Reflective-Band Data. Ieee Transactions on Geoscience and Remote Sensing, 2010. 48(1): p. $556-574$.

[12] Kong, X., et al. Cloud and shadow detection and removal for Landsat-8 data. in Eighth International Symposium on Multispectral Image Processing and Pattern Recognition. 2013. International Society for Optics and Photonics.

[13] Lulla, K., et al., The Landsat 8 is ready for geospatial science and technology researchers and practitioners. Geocarto International, 2013. 28(3): p. 191-191.
[14] Markham, B.L., et al. Landsat Data Continuity Mission, now Landsat-8: six months on-orbit. in SPIE Optical Engineering+ Applications. 2013. International Society for Optics and Photonics.

[15] USGS. Frequently Asked Questions about the Landsat Missions. $2013 \quad 11 / 27 / 13$; Available from: http://landsat.usgs.gov/band_designations_landsat_satellites.p hp.

[16] Guo, X.L., et al., Comparison of Laboratory and Field Remote Sensing Methods to Measure Forage Quality. International Journal of Environmental Research and Public Health, 2010. 7(9): p. 3513-3530.

[17] Black, S.C., et al., Estimation of grassland CO(2) exchange rates using hyperspectral remote sensing techniques. International Journal of Remote Sensing, 2008. 29(1): p. 145155 .

[18] Xu, D., et al., Measuring the dead component of mixed grassland with Landsat imagery. Remote Sensing of Environment, 2014. 142: p. 33-43.

[19] Richter, R., et al. Atmospheric/Topographic Correction for Satellite Imagery. ATCOR-2/3 User Guide, Version 8.3. 2013; October 2013:[Available from: http://www.rese.ch/pdf/atcor3_manual.pdf.

[20] NASA. Preliminary Spectral Response of the Operational Land Imager In-Band, Band-Average Relative Spectral Response. 2014; Available from: http://landsat.gsfc.nasa.gov/?p=5779.

[21] Bogrekci, I., et al. The effects of soil moisture content on reflectance spectra of soils using UV-VIS-NIR spectroscopy. in Proc. 7th Int. Conf. Precision Agric. 2004.

[22] Guo, X., et al., Monitoring grassland health with remote sensing approaches. Prairie Perspectives, 2005. 8: p. 11-22. 